\title{
Contributions to Positive Sexuality from the Zen Peacemakers
}

\author{
Eli Pliskin \\ pliskin.eli@gmail.com
}

\begin{abstract}
Inspired by a lineage of Zen Buddhism, Zen Peacemakers provides a transformational path that integrates theory and practices, including meditation, Nonviolent Communication (NVC), the Way of Council, Bearing Witness Retreats, activism, and social enterprise. As an ordained Minister in the lineage who personally apprenticed with co-founder Bernie Glassman, I have seen these principles and practices provide great benefit. This article will highlight some of the many possible theoretical and practical points of resonance between Zen Peacemaking and the Eight Dimension Model of the Center for Positive Sexuality (CPS) (Williams, Thomas, Prior, \& Walters, 2015) by suggesting how this rich and cohesive peacemaking methodology might help actualize each of the eight dimensions of positive sexuality, one dimension at a time. The eight dimensions are: (a) peacemaking, (b) multiple ways of knowing, (c) open, honest communication, (d) ethics, (e) application across all levels of social structure, (f) strengths, wellbeing, and happiness, (g) the recognition that individual sexuality is unique and multifaceted, and (h) humanization.
\end{abstract}

\section{Introduction}

This article considers sexuality as a microcosm of patterns of suffering and liberation that are recognized in the Buddhist tradition as essential to the human experience. Throughout this article, I will use the term sexuality to include sexual orientation, sexual desire, sexual activity, gender, and intimate relationships. While other treatments of positive sexuality (Glick, 2000; Ivanski \& Kohust, 2017; Queen \& Comella, 2008) share with the CPS eight-dimension model respect for sexual plurality in terms of diverse genders, sexualities, and relationship styles, this article suggests how plurality may be applied to epistemic, political, and ethical arenas as part of a transformative and liberating approach to sexuality and life.

\section{Positive Sexuality Encourages Peacemaking}

Each of the eight CPS dimensions may realize the Three Tenets of the Zen Peacemakers: (a) not-knowing, (b) bearing witness, and (c) doing the actions that arise from not-knowing and bearing witness. This article seeks to continue the following tradition articulated by Glassman (1998): “As a Zen teacher, I was always asking myself what new practices I could develop to help my students experience the oneness of life... And what are the peacemaking forms that will help all beings experience their interdependence?”

Linking peacemaking to the Three Tenets, Glassman (1998) inquired in Bearing Witness: A ZenMaster's Lessons in Making Peace, "What is Peacemaking? You will not find the answer in this book. This is not a book of answers, for there is little energy in answers. This is a book of... living a questioning life, a life of unknowing. If we're ready to live such a life, without fixed ideas or answers, then we are ready to bear witness to every situation, no matter how 
difficult, offensive, or painful it is. Out of that process of bearing witness the right action of making peace, of healing, arises.”

A commitment to not-knowing is compatible with understanding knowledge as tentative, incomplete, fallible, subjective, and constructed. In addition to defining not-knowing as letting go of fixed ideas, this article (following the Zen Peacemaker tradition) will use a specific sense of knowing, which involves clinging to fixed ideas, as the opposite of not-knowing. This sense of knowing is found in rigid dogma and biased assumptions. Glassman associated this type of knowing with certainty, dualism, and separation (1998).

I propose that sex negativity is knowing in the realm of sexuality. Sex negativity can take various forms. One form is the assumption that sex is bad. This bias sees sexuality as sinful, pathological, or harmful. Defined as such, other types of sex negativity assert that only particular types of sexual expression are legitimate. Heteronormativity, which is dominant in many cultures, may privilege sex for the purpose of reproduction between a husband and wife and negate all other forms of sexuality.

Examples of some signs that indicate whether or not specific cultures are sex positive or negative include the following. Conservative religion has been associated with attitudes that are not supportive of gays and lesbians (Brown \& Henriquez, 2008). By defining a narrow range of sexuality as acceptable, these groups may be considered less sex positive. By contrast, participants of the BDSM sub-culture have demonstrated lower rates of sexist rape-supportive beliefs than the rest of the population (Klement et al., 2017). Researchers attribute these results to socialization in affirmative consent practices promoted by community activists. Therefore, in addition to being inclusive of practitioners of a variety of kinks, this subculture may also cultivate a more inclusive attitude with regard to gender.

Counterintuitively, the belief that sex is good could be a form of sex negativity if it involves imposing the belief that sex in general, or a particular type of sex, is good for everyone at all times. Therefore, while "slut-shaming" would be one form of sex negativity, "prudeshaming” could be another. Positive sexuality respects the lifestyles, choices, and needs of wideranging groups including swingers, asexuals, heterosexual spouses, those who practice celibacy, and those recovering from sexual trauma.

Forms of sex negativity and positivity vary from person to person, sometimes based on cultural patterns and, other times, individual idiosyncrasy. In contrast to sex negativity, which negates those who are deemed to fall outside of definitions of acceptability, sex positivity and peacemaking affirm and liberate. Sex negativity may result in stigma, discrimination and physical aggression, while peacemaking appreciates the wide range of diversity that naturally occurs in humanity.

\section{Positive Sexuality Embraces Multiple Ways of Knowing}

Viewed through the lens of the Three Tenets of the Zen Peacemakers (not-knowing, bearing witness, and taking action), the CPS dimension of embracing multiple ways of knowing is rooted in the fundamental limitations of knowing. The illusion of certain knowing creates 
violence while not-knowing may contribute to peace with ourselves, with others, and with all that is. In his later years, Glassman would often paraphrase the Dude from the film The Big Lebowski: "that's just your opinion" (Bridges \& Glassman, 2014). Glassman said that "when we live in a state of knowing, rather than unknowing, we're living in a fixed state of being where we cannot experience the endless unfolding of life, one thing after another... our notions of what should happen block us from seeing what actually does happen. We get upset because our expectations are not met. When we can let go of them, we are in accord with things as they arise" (Glassman, 1998).

When practicing not-knowing by avoiding clinging to any particular way of knowing, many ways of understanding and interpreting the world become possible. The CPS model encourages multiple ways of knowing in the field of sexology in terms of disciplines, theoretical paradigms, and research methods (Williams et al., 2015). Additionally, peacemaking may realize multiple ways of knowing by integrating the wisdom of the intellect with that of the heart and that of the body.

\section{Positive Sexuality Promotes Open, Honest Communication}

To use communication as a tool for peacemaking, sexuality involves practicing the Three Tenets of the Zen Peacemakers (not-knowing, bearing witness, and taking action) to transcend a separate sense of self in relationships. Techniques practiced in the Zen Peacemakers, including the Way of Council and Nonviolent Communication (NVC), may be applied in a variety of settings, including intimate relationships.

The Zen Peacemaker tradition may contribute to the field of sexuality because of its application of principles of meditation to interpersonal dynamics. Just like one returns to the object of attention when distracting thoughts come up during meditation, the intention of "listening from the heart" in the Way of Council involves learning how not to get hung up on judgements or rehearsing thoughts. The structure of passing a talking piece slows down the process and creates a container that can hold multiple truths side by side. The practice helps participants transcend their limited individual perspective and bear witness to the whole (Zimmerman \& Coyle, 2009). The Way of Council is utilized in both Mindfulness-Based Stress Reduction (MBSR) as well as interventions, which specifically help couples address relationship problems (Baer, 2015).

Nonviolent Communication (NVC) involves encouraging clear expression of observations, feelings, needs, and requests (Rosenberg, 2003). It recognizes subtle types of violence caused by passing off subjective judgements as objective observations. By encouraging requests instead of demands, NVC can support people to respect the autonomy and consent of others. Practicing these methods can be a powerful act of intimacy and can facilitate negotiations about sexual activity and relationship in which partners express and respond to desires and boundaries. One survey of literature finding support for the efficacy of NVC summarized that "what becomes salient in this review is an intimate interrelation among empathy enhancement, conflict resolution skills, communication skills and relationships improvement, which is consistent with previous research on empathy and pro-social behavior” (Juncadella, 2013, p. 60). 
In one set of interviews, both therapists and clients identified NVC as a helpful technique for navigating polyamorous relationships in particular (Calhoun-Shepard, 2019).

\section{Positive Sexuality Reflects Ethics}

Viewed through the lens of peacemaking methods, all eight dimensions of positive sexuality inform lifelong practices that impact how we treat ourselves and others. Peacemaking ethics come out of bearing witness to ourselves and others in a circumstantial and situational way. Peacemaking morality is rooted in not-knowing and bearing witness while moralism is based on knowing. Moralism involves rigidly applying principles of right and wrong even when those principles do not promote human welfare. According to Rosenberg, the creator of Nonviolent Communication (NVC), "one kind of life-alienating communication is the use of moralistic judgements that imply wrongness or badness on the part of people who do not act in harmony with our values... blame, insults, put-downs, labels, criticism, comparisons, and diagnoses are all forms of judgement... it is a language rich with words that classify and dichotomize people and their actions” (Rosenberg, 2003). By promoting fixed ideas, these forms of language reinforce the rigid forms of knowing for which not-knowing is the antidote. Sexuality is one of the favorite targets of moralists. Advocates of the sex addiction model are one of many examples of imposing moralistic judgements on sexuality while using the language of mental health (Ley, 2012).

Positive sexuality is rooted in an intersubjective sense of morality and ethics that is sensitive to circumstance and promotes social justice. The CPS scholars argue that ethical sexual behavior be based on caution, communication, consent, and caring (Williams, Christensen, Capous-Desyllas, 2016; Williams, Thomas, Prior \& Christensen, 2014). Critiquing previous approaches that emphasize a rational process of objective cognitive discernment, the CPS authors are inspired by a feminist ethic of care that sees morality situated within evolving relationships (Williams et al., 2014).

Glassman's circumstantial approach to morality is compatible with the ethics promoted by CPS scholars. Glassman described an approach to the 10 Buddhist precepts that takes into account literal, absolute, and subjective perspectives (Glassman, 2002). From the literal standpoint, we must follow the letter of the law without exception. From the absolute standpoint, it is impossible to violate a precept because there is no fixed self to violate it (more on this later). The subjective standpoint takes into account time, place, people, and quantity.

A peacemaking sexuality ethic can include practices for continually aligning oneself more strongly with ethical conduct as well as addressing conflict and ethical breaches within communities. For example, sexuality education can foster respect for consent and the sexual rights of others (Hambrick, Grove, Warwick, \& Smith, 2014). INCITE! Women of Color Against Violence have disseminated a restorative justice model for addressing sexual assault (INCITE!, 2016). Glassman encouraged regularly practicing “at-one-ment” as we understand the ways we inevitably violate precepts and seek to do better (Glassman, 2002). 


\section{Positive Sexuality is Applicable Across All Levels of Social Structure}

Positive sexuality can be applied across what social workers call the micro, mezzo, and macro levels (Schaefor \& Horesji, 2015). A resonant principle in the Zen Peacemakers is that actions that follow not-knowing and bearing witness should impact all levels of social structure. Paraphrasing Kobo Daishi, the 8th Century founder of Japan's tantric Buddhist sect, Glassman often said that "the way you could tell the depth of a person's enlightenment is by how they serve others" (Meissner, 2011). Glassman explained further that "If the depth of my... experience of the Oneness of life is the skin and bones that I call Bernie, then my focus is going to be on Bernie... If the depth of your experience of Oneness is your family, you're going to be doing things for your family... If the depth of your experience is your society, you're going to be doing works for your society... From my standpoint, it is still doing things for myself. It is just that myself is the society” (Meissner, 2011). The Zen Peacemakers emphasize service on all levels of society while diminishing separation between self and other through a path integrating personal development, relationships, social entrepreneurship, and activism.

Sex negativity may involve neglecting to bear witness to some social level of sexuality. It may involve an atomistic individualism that does not take into account social positions or a totalitarian collectivism that does not account for individual variation. Bearing witness to all levels of social structure should integrate personal and social transformation. The social work concept of micro, mezzo, and macro levels of practice (Schaefor \& Horesji, 2015) is useful here. Positive sexuality at the micro level involves sexual self-pleasure, an individual's understanding of their own sexuality, and sexuality issues among family, friends, and sexual or intimate partners.

Two of the most salient aspects of macro level practice are government and institutional policy and social norms. Policy related to sexuality includes laws that impact sex education, marriage, sex work, and protection from discrimination for sexual minorities. While the macro level addresses organizations, communities, societies, states, nations and the whole world, the mezzo level addresses small groups, extended community, peers, and school or work and neighbors.

\section{6. “Positive” Refers to Strengths, Wellbeing, and Happiness}

Sex-negative bias can threaten our ability to bear witness to the world as it is in a number of ways. Sex negativity can take the form of excessive or exclusive focus on the negative and result in failing to appreciate strengths, resilience, and other beneficial aspects of sexuality. Another form of sex negativity is when sexual practices are inaccurately associated with pathology as a result of cultural bias that is not founded on systematic empirical observation. Related to such prejudice is when distress associated with sexual behavior is inaccurately attributed to inherent characteristics of the sexual behavior when the harm of social stigma is actually the cause of the distress. An example of such bias can be seen with understanding of sadomasochism as psychological disorder since its inclusion in Krafft-Ebing's Psychopathia Sexualis (1965), originally published in the late 19th Century. Recent research has, by contrast, revealed that sexual sadism and masochism are not associated with pathology and may be associated with various psychological benefits (Connolly, 2006; Cross and Matheson, 2006; 
Hébert \& Weaver, 2014; Powls \& Davies, 2012; Richters, de Visser, Rissel, Grulich, \& Smith, 2008; Sandnabba, Santtila, \& Nordling, 1999; Wismeijer \& van Assen, 2013).

Glassman's use of the analogy of making a meal resonates with defining positive as strengths, wellbeing, and happiness. In Instructions to the Cook: A Zen Master's Lessons in Living a Life that Matters Glassman encouraged readers (Glasman \& Fields, 1996) to make the best meal possible with the ingredients available. According to Glassman, looking at the positive is rooted in bearing witness to the world clearly as it is. To make the "supreme meal," he stated, it is important to let go of fixed ideas by not getting hung up on the ingredients we do not have but rather to bear witness to what is in front of us. Glassman also taught that it is important to use all the ingredients and leave nothing out. The book illustrated the application of these principles to all areas of community life through the social enterprise and service work of Glassman and his colleagues in Yonkers, NY. The Greyston Bakery in Yonkers practices the motto of making brownies to hire people instead of hiring people to make brownies. Creating products for customers including Ben \& Jerry's, Greyston practices an open-hiring policy to challenge the discrimination of formerly incarcerated people.

Glassman's teaching about making the best meal possible resonates with ways that mental health and sexology leaders have sought to balance bias focusing on pathology and deficit. To focus on the positive in sexuality means increasing trust in the human capacity to pursue or not pursue fulfilling sexual experiences (Williams et al, 2015). Positive psychologists have discovered that leisure activities and relationships are more strongly correlated with Subjective Well-Being than class, income, or ethnicity (Deiner, 2000). Since sexuality is associated with leisure and relationships, sexuality is an area strongly influenced by our choice and agency, which may have a great impact on happiness. Positive psychology seeks to balance the tendency to focus on diagnosable disorders, including sexual disorders. Such an approach also provides an alternative to approaches such as Kraff-Ebing, which automatically label less common sexualities as pathological.

\section{Individual Sexuality is Unique and Multifaceted}

Bearing witness to the wholeness of humanity includes acknowledging, respecting, and affirming a wide range of sexual diversity while also maintaining an attitude of not-knowing with regards to individual identity. Annual Auschwitz Bearing Witness Retreats are one-way Zen Peacemakers have been exploring diversity for over two decades. On organizing the Auschwitz Bearing Witness retreat, Glassman said, "It struck me that this was a place where one answer to diversity existed and that was to kill everybody that was not like you.” (Meissner, 2011). The Auschwitz retreat, by contrast, was organized to include as much diversity as possible. What would a bearing witness retreat that explored sexuality look like?

Peacemaking involves striving to appreciate and engage a wider and wider diversity of people. Gayle Rubin (1984) illustrated how a hierarchy of sexual value excludes many sexuality practices and identities. This sex negativity has a logic of its own independent from other forms of oppression. In Rubin's view, sex negativity intersects with sexism, heteronormativity, racism, classism, and other forms of oppression. Positive sexuality, therefore, may fit into an intersectional framework of working for liberation of all oppressed groups. 
Respect for individuality and appreciation for fluidity are embedded in both queer theory and Buddhism. Bearing witness to the whole of humanity includes the recognition that, in the words of queer theorist Judith Butler, "No matter whether one feels one's gendered and sexed reality to be firmly fixed or less so, every person should have the right to determine the legal and linguistic terms of their embodied lives” (Williams, 2014).

A sense of not-knowing may compliment respect for individual identity. Summarizing a foundational Buddhist principle, Glassman said, "We do not have a self or fixed identity. Because everything is changing, what actually exists is nothing” (2002, p. 42). Michel Foucault, another influential figure in queer theory, struck a similar tone when he said that "if identity is only a game... it is useful." He went on to say that "the relationships we have to have with ourselves are not one of identity, rather, they must be relationship of differentiation, of creation, of innovation” (Gallagher, \& Wilson, 1984).

\section{Positive Sexuality is Humanizing}

Glassman talked about the tendency to define certain people as “other.” Describing phenomena ranging from ignoring people one does not like to hate crimes and genocide, Glassman talked about the way people treat those outside of their “club.” Dehumanization is a way to define people as fundamentally outside of one's club. By contrast, recognizing the human dignity of others, or humanization, as a form of peacemaking involves practicing the three tenets to transcend a separate sense of self in relation to social groups. Humanization involves expanding the circle of those we include in our club and eliminating the separation between those within our club and those outside of it.

Humanization takes different forms with different types of groups. One form is with identities and practices that are misunderstood and unjustly stigmatized, such as sex workers. Using inclusive language that respects diversity also reflects the dimension of respecting unique and multi-faceted individual sexuality (Williams et al., 2015).

Humanization calls us to examine how we treat people who fall short of the requirements expressed by the dimension of ethics. In addition to remembering the victims of genocide at the Auschwitz retreat, the Zen Peacemakers "remember" the German Nazi officers that ran the camp. Without forgiving or condoning, remembering acknowledges that the Nazis were human and acknowledges the "perpetrator" in each of us. Illustrating the harm of dehumanizing those who may fall short of ethical standards, Williams argued that sex-negative policy that aims to punish sex offenders dehumanizes them and ironically increases the likelihood of reoffence by making those people more isolated, depressed, and desperate (Williams, Thomas, \& Prior, 2015).

It is also important to humanize those who advocate attitudes and policies that unjustly condemn or limit the sexual freedom of others. In doing so, we work to avoid othering those we experience as othering us. Promotors of sex negativity may include those who advocate for things such as conversion therapy targeting homosexuals, abstinence-only education, or media images that present a narrow range of women as attractive. By merely defining a term like "sex positivity," we risk creating dualism with "sex negativity." The humanizing dimension asks how we may transform sex negativity without perpetuating the violence of separation and dualism. 


\section{Conclusion}

The Zen Peacemakers draw from millennia of spiritual wisdom, as well as scientifically informed approaches to mindfulness. The Zen Peacemakers philosophy informs my efforts as a social worker and sexuality educator. My experience is that the techniques of meditation, council, NVC, bearing witness retreats, and social enterprise fit together in powerful ways. Inspired by this tradition, I helped found a pay-what-you-can community café and organized a bearing witness retreat on racism in the food system. I believe that the collection of Zen Peacemaking techniques applied in conjunction with each other may offer synergistic results that help reduce suffering more effectively than if applied separately.

Whether or not the teachings of Buddhism (or any particular religion) resonate with you, this article aspires to offer you perspectives and practices that may reduce suffering for yourself and others in the field of sexuality. This article seeks to ask questions and provoke conversations. It seeks to inspire possibilities for individuals, people in intimate relationships, communities, and beyond. My hope is that further work may explore applications of peacemaking sexuality such as individual, relationship and group therapy, sexuality education, sexuality-related bearing witness retreats, and beyond.

\section{References}

Baer, R. A. (2015) Mindfulness-Based Treatment Approaches: Clinician's Guide to Evidence Base and Applications. New York, NY: Academic Press.

Bridges, J. \& Glassman, B. (2014). The Dude and the Zen Master. New York, NY: Plume.

Brown, J. M., \& Henriquez, E. (2008). Sociodemographic predictors of attitudes toward gays and lesbians. Individual Difference Research, 6(3), 193-202.

Calhoun-Shepard, Rebecca, "Polyamorous Millennials in Therapy: Interpreting Experiences to Inform Care" (2019). Dissertations \& Theses. 516. https://aura.antioch.edu/etds/516

Connolly, P. H. (2006). Psychological functioning of bondage/domination/sado-masochism (BDSM) practitioners. Journal of Psychology and Human Sexuality, 18(1), 79-120. https://doi.org/10.1300/J056v18n01_05.

Cross, P. A., \& Matheson, K. (2006). Understanding sadomasochism: An empirical examination of four perspectives. Journal of Homosexuality, 50(2/3), 133-166. DOI: 10.1300/J082v50n02_07.

Deiner, E. (2000). SWB: The science of happiness and a proposal for a national index. American Psychologist, 55 34-41. DOI:10.1037/0003066X.55.1.34.

Gallagher, B. \& Wilson, A. (1984, August 7) Interview with Michel Foucault The Advocate 400, pp. 26-58.
Glassman, B. \& Fields, R. (1996). Instructions to the Cook: A Zen Master's Lessons in Living a Life That Matters. Boston, MA: Shambhala Publications.

Glassman, B. (1998). Bearing Witness: A Zen Master's Lessons in Making Peace. New York, NY: Bell Tower.

Glassman, B. (2002). Infinite Circle: Teachings in Zen. Boston, MA: Shambhala Publications.

Glick, E. (2000). Sex positive: Feminism, queer theory, and the politics of transgression. Feminist Review, 64(1), 19-45. https:// doi.org/10.1080/014177800338936

Hambrick, A., Grove, J., Warwick, J., \& Smith, J. (2014). Rounding the Bases: A Sex Positive Approach to Violence Prevention. Retrieved from https://www.youtube.com/watch?v=BWj1clIHP NQINCITE! (2016) Color of violence: The INCITE! Anthology. Durham \& London: Duke University Press.

Hebert, A., \& Weaver, A. (2014). An examination of personality characteristics associated with BDSM orientations. The Canadian Journal of Human Sexuality, 23(2), 106-115. doi:10.3138/cjhs.2467

Ivanski, C \& Kohut, T. (2017). Exploring definitions of sex positivity through thematic analysis. The Canadian Journal of Human Sexuality 26(3), 216-225. https://doi.org/10.3138/cjhs.2017-0017. 
Juncadella, C. M. (2013) "What is the impact of the application of the Nonviolent communication model on the development of empathy? Overview of research and outcomes.” Retrieved from https://www.cnvc.org/sites/default/files/NVC_Re search_Files/Carme_Mampel_Juncadella.pdf.

Klement, K. R., Sagarin, B. J., \& Lee, E. M. (2017). Participating in a culture of consent may be associated with lower rape-supportive beliefs. Journal of Sex Research, 54(1), 130-134. doi: 10.1080/00224499.2016.1168353.

Ley, D. (2012). The Myth of Sex Addiction. Plymouth, UK: Rowman \& Littlefield Publishers, Inc.

Meissner, T. (2011, March 5). The Secular Buddhist Episode 57: Bernie Glassman: Socially Engaged Buddhism. [Audio podcast] Retrieved from https://secularbuddhism.org/2011/03/25/episode57-bernie-glassman-socially-engaged-buddhism/

Powls, J., \& Davies, J. (2012). A Descriptive Review of Research Relating to Sadomasochism: Considerations for Clinical Practice. Deviant Behavior,33(3), 223-234. doi:10.1080/01639625.2011.573391

Queen, C., \& Comella, L. (2008). The Necessary revolution: Sex-positive feminism in the postBarnard era. Communication Review, 11(3), 274-291. https://doi.org/10.1080/ 10714420802306783

Richters, J., Visser, R. O., Rissel, C. E., Grulich, A. E., \& Smith, A. M. (2008). Demographic and Psychosocial Features of Participants in Bondage and Discipline, "Sadomasochism” or Dominance and Submission (BDSM): Data from a National Survey. The Journal of Sexual Medicine, 5(7), 1660-1668. doi:10.1111/j.17436109.2008.00795.x

Rosenberg, M. (2003). Nonviolent Communication: A Language of Life. Encinitas, CA: Puddle Dancer Press.

Rubin, G. (1984) “Thinking Sex: Notes for a Radical Theory of the Politics of Sexuality." in Pleasure and Danger: Exploring Female Sexuality. (1992) Ed. Carole S. Vance. London: Pandora. 267-293.

Sandnabba, N. K., Santtila, P., \& Nordling, N. (1999). Sexual behavior and social adaptation among sadomasochistically-oriented males. Journal of Sex Research, 36, 273-282. https://doi.org/10.1080/00224499909551997.
Schaefor, B \& Horesji, C. (2015) Techniques and guidelines for social work practice. Boston, MA: Pearson. von Krafft-Ebing, R. (1886/1978). Psychopathia sexualis. New York: Stein \& Day/Scarborough.

Williams, C. (2014, May 1) Judith Butler addresses TERFs and the work of Sheila Jeffreys and Janice Raymond. The TERFs. Retrieved from http://theterfs.com/2014/05/01/judith-butleraddresses-terfs-and-the-work-of-sheila-jeffreysand-janice-raymond/

Williams, D J, Christensen, M. C., Capous-Desyllas, M. (2016) Social work practice and sexuality: Applying a positive sexuality model to enhance diversity and resolve problems. Families in Society: The Journal of Contemporary Social Services, 97 (4), 287-294

Williams, D J, Thomas, J. \& Prior, E. (2015). Moving Full-Speed Ahead in the Wrong Direction? A Critical Examination of US SexOffender Policy from a Positive Sexuality Model. Critical Criminology. 10.1007/s10612015-9270-y.

Williams, D J, Thomas, J., Prior, E \& Walters, W. (2015) Introducing a multidisciplinary framework of positive sexuality. Journal of Positive Sexuality, 1, (February). 6-11. Retrieved from https://journalofpositivesexuality.org/wpcontent/uploads/2015/02/IntroducingMultidisciplinary-Framework-of-PositiveSexuality-Williams-Thomas-Prior-Walters.pdf

Williams, D J, Thomas, J., Prior, E. \& Christensen, M. (2014). From "SSC" and "RACK" to the "4Cs": Introducing a new Framework for Negotiating BDSM Participation. Electronic Journal of Human Sexuality, 17, Retrieved from http://www.ejhs.org/volume17/BDSM.html

Wismeijer, A. A., \& Van Assen, M. A. (2013). Psychological Characteristics of BDSM Practitioners. Journal of Sexual Medicine. doi:10.1111/jsm.12192

Zimmerman, J. \& Coyle, (2009) V. The Way of Council 2nd Edition. Spring City, PA: Bramble Book 